\author{
Annemarieke Rutten \\ Matthijs F. L. Meijs \\ Alexander M. de Vos \\ Peter R. Seidensticker \\ Mathias Prokop
}

\section{Biphasic contrast medium injection in cardiac CT: moderate versus high concentration contrast material at identical iodine flux and iodine dose}

Received: 19 November 2009

Revised: 4 January 2010

Accepted: 7 February 2010

Published online: 20 March 2010

(C) The Author(s) 2010.

This article is published with open access at Springerlink.com

\author{
A. Rutten $(\bowtie) \cdot$ M. Prokop \\ Department of Radiology, \\ Room E01.132, \\ University Medical Center Utrecht, \\ Heidelberglaan 100, \\ 3584 CX Utrecht, The Netherlands \\ e-mail: a.rutten@umcutrecht.nl \\ Tel.: +31-88-7556687 \\ Fax: +31-30-2581098 \\ M. F. L. Meijs · A. M. de Vos \\ Department of Cardiology, \\ University Medical Center Utrecht, \\ Utrecht, The Netherlands \\ P. R. Seidensticker \\ Bayer-Schering AG, \\ Berlin, Germany
}

\author{
Abstract Objective: To prospec- \\ tively investigate the influence of \\ contrast material concentration on \\ enhancement in cardiac CT by using a \\ biphasic single-injection protocol. \\ Methods: Sixty-four-row multidetec- \\ tor cardiac CT angiography was \\ performed in 159 patients randomised \\ to a moderate or high contrast medi- \\ um concentration. Contrast material \\ injection included a first phase for \\ enhancement of the coronary arteries \\ and a second phase, at half the iodine \\ flux, targeted at enhancement of the \\ right ventricle. Contrast medium \\ injection was followed by a saline \\ flush. For both concentrations, \\ injection duration (and thus total \\ iodine dose) was adapted to the \\ duration of the CT data acquisition \\ and iodine flux was adjusted to \\ patient weight. Attenuation was
}

measured at various levels in the heart and vessels and the two concentrations compared, overall and per weight group. Results: Enhancement of the aorta and left ventricle was significantly greater with the moderate than with the high concentration contrast medium. This remained true for the two higher weight groups. No difference was found in the lowest weight group or in the right ventricle and pulmonary outflow tract. Conclusion: With a biphasic injection protocol, enhancement of the aorta and left ventricle was weaker with the higher concentration of contrast material.

Keywords Computed tomography · Coronary CT angiography - Contrast medium concentration - Contrast medium injection protocol

\section{Introduction}

The new generations of multidetector computed tomography (CT) ( $\geq 64$-detector row) have substantially decreased the duration of CT data acquisition for cardiac $\mathrm{CT}$ angiography (CTA). These new systems even allow ECG-synchronised $\mathrm{CT}$ of the complete thorax for a triple rule-out protocol within a single breath-hold [1]. Adjustments to contrast medium injection protocols are required to obtain a high level of arterial enhancement faster and to combine left ventricular/ coronary artery enhancement with right ventricular/pulmonary artery enhancement. Recently biphasic injection protocols have been described that achieve this combination $[1,2]$.
Arterial enhancement is determined by patient-related factors (e.g. blood volume, cardiac output) and the contrast medium injection parameters (e.g. contrast material concentration, contrast material volume, flow rate, added saline chaser bolus) [3-5]. Iodine flux (flow rate $\times$ iodine concentration) and iodine dose (contrast material volume $\times$ iodine concentration) are considered to be the determining factors for enhancement $[4,6]$. There are publications that suggest that a higher iodine concentration provides superior enhancement characteristics, but theoretically this superior enhancement can also be achieved by an increase in contrast medium injection rate (iodine flux in grams of iodine injected per second $=$ injection rate $\times$ concentration) $[3,4,6-9]$. 
We evaluated the effect of contrast medium concentration on cardiac and arterial enhancement in 64-row multidetector cardiac CT by using a biphasic injection protocol for differential enhancement of the coronary arteries and the right ventricle. High initial contrast injection rates with adjustments for patient weight and duration of $\mathrm{CT}$ data acquisition were applied to obtain optimal enhancement of the coronary arteries for assessment of coronary artery disease and of both the left and the right ventricle for functional analyses. While two different contrast medium concentrations were used, iodine flux and iodine dose were kept constant by adapting contrast medium volume and injection rate. Our hypothesis was that no substantial differences in enhancement between the two contrast medium concentrations would be detected.

\section{Materials and methods}

The institutional review board granted permission to perform this study. All patients signed informed consent. We included 182 consecutive patients scheduled for cardiac CT. They received contrast medium with either $300 \mathrm{mg}$ iodine (I)/ml or $370 \mathrm{mg} \mathrm{I} / \mathrm{ml}$ (Iopromide, Schering, Berlin, Germany) during the examination. Sixty-four-row multidetector cardiac CT was performed (Brilliance 64, Philips Medical Systems, Cleveland, OH, USA). CT parameters are summarised in Table 1.
Exclusion criteria Patients were excluded if a needle smaller than 18 gauge $(G)$ was used for intravenous injection because of the small vessel size, as an 18-G needle was needed to accommodate the applied flow rates, or if the imaging range was extended beyond the region of the heart. Twenty-three of the 182 consecutive patients undergoing cardiac CT were excluded. A $20-G$ needle was used in 6 patients because of the small vessel size, 8 patients had to undergo a cardiac CT with an extended imaging range, e.g. bypass graft evaluation, and 9 patients were excluded because of deviations from the CT protocol, such as change of post-threshold delay, which could influence contrast enhancement.

\section{Contrast medium injection protocol}

Randomisation to one of the two contrast medium concentrations was performed on a per day basis for logistic reasons, e.g. changing contrast material takes valuable time, and wastage of contrast medium remaining in the injector after the previous contrast-enhanced CT examination. We applied a biphasic contrast injection protocol modified from Garcia et al. [10] with two connected phases of contrast medium injection immediately followed by a saline flush of $30 \mathrm{ml}$ injected with a dual syringe injector (Stellant D, Medrad, Indiana, PA, USA). This protocol was used to prevent washout of the right ventricle to allow functional analyses of both

Table 1 Imaging parameters

\begin{tabular}{|c|c|}
\hline Imaging parameter & Value \\
\hline Collimation (mm) & $64 \times 0.625$ \\
\hline Direction & $\downarrow$ \\
\hline Imaging range & $15 \mathrm{~mm}$ above highest coronary artery to $15 \mathrm{~mm}$ below heart \\
\hline ECG synchronisation & Retrospective gating \\
\hline Location bolus tracker ROI & In descending aorta at start of planned imaging range \\
\hline Bolus tracker threshold (HU) & 100 \\
\hline Start delay & $8 \mathrm{~s}$ after reaching threshold \\
\hline Imaging length $(\mathrm{cm})$ & $10-16$ (average 12) \\
\hline Imaging duration (s) & $8-11$ (average 10) \\
\hline Pitch & 0.2 \\
\hline Peak tube potential $(\mathrm{kVp})$ & 120 \\
\hline Tube current (mAs) & $500-1,000$ (depending on patient size) \\
\hline Dose modulation & ECG-based at $70 \%$ to $80 \%$ phase if regular heart rate below $60 \mathrm{bpm}$ \\
\hline FOV $(\mathrm{mm})$ & 205 \\
\hline Matrix & $512 \times 512$ \\
\hline Reconstruction filter & Cardiac B (medium) \\
\hline Reconstructed section thickness (mm) & 0.9 \\
\hline Reconstructed section increment (mm) & 0.45 \\
\hline Reconstructed phases & Every $10 \%$ of RR interval \\
\hline
\end{tabular}


ventricles in addition to the coronary artery analysis. A similar contrast medium injection protocol is suggested for triple rule-out studies to achieve adequate enhancement of the aorta, coronary arteries and the pulmonary artery [1].

The first contrast medium injection phase is similar to the single contrast medium injection phase commonly used for cardiac CTA and yields sufficient enhancement of the coronary arteries $[5,11,12]$. The second, directly consecutive, contrast medium injection phase was applied to prevent washout of the right ventricle, a portion of the circulation proximal to the coronary arteries, and thus to allow analysis of left and right ventricular function, including left ventricular wall thickness and thickening, which is not possible with complete washout of the right ventricle.

Each patient was assigned to one of three weight categories, each with its own iodine flux $(\mathrm{g} / \mathrm{s})$ for the first injection phase $(<70 \mathrm{~kg}: 1.6 \mathrm{~g} / \mathrm{s} ; 70-85 \mathrm{~kg}: 1.8 \mathrm{~g} / \mathrm{s} ;>85 \mathrm{~kg}$ : $2.0 \mathrm{~g} / \mathrm{s}$ ) (Table 2). Iodine flux was independent of the contrast medium concentration used. The duration of the first injection phase was determined in a similar way to that for single phase CTA, and was calculated from the duration of CT data acquisition plus $8 \mathrm{~s}$, the duration of the postthreshold delay for bolus triggering.

Iodine flux in the second contrast medium phase was $50 \%$ of the flux in the first phase. Injection duration for the second phase was fixed at $10 \mathrm{~s}$. Between the two contrast medium injection phases and between contrast medium injection and saline flush no time delay occurred. The flow rate $(\mathrm{ml} / \mathrm{s})$ during each phase of the contrast medium injection and the volume of contrast medium $(\mathrm{ml})$ to be injected during each phase was calculated in a spreadsheet program (Excel, Microsoft Office 2003, Redmond, WA) (Table 2). Maximum flow rate was $6.7 \mathrm{ml} / \mathrm{s}$ with a contrast medium concentration of $300 \mathrm{mg} \mathrm{I} / \mathrm{ml}$. The total iodine dose $(\mathrm{g})$ injected could be calculated by multiplying iodine flux and injection duration and was also independent of contrast medium concentration. The $370 \mathrm{mg} \mathrm{I} / \mathrm{ml}$ contrast material was preheated to $37^{\circ} \mathrm{C}$ before use to decrease the viscosity. Bolus tracking with a region of interest (ROI) in the descending aorta at the start of the imaging range was used to time the CT data acquisition which started $8 \mathrm{~s}$ after reaching the threshold value of $100 \mathrm{HU}$. Time to threshold and the maximum injection rate reached were recorded.

\section{Enhancement evaluation}

Vascular enhancement was measured by placing ROIs of $1 \mathrm{~cm}^{2}$ in the left and right ventricle and the descending aorta at three levels (cranial, mid and caudal) and in the ascending aorta and pulmonary artery, right above the aortic and pulmonary valve, respectively. Contrast enhancement in these structures was considered representative of enhancement in the coronary arteries with the advantages that large ROI sizes and standardised measurement locations could be used. At each measurement site ROIs were placed on three adjacent slices and attenuation values were averaged before further analysis. Visible artefacts were excluded from the measurements. Measurements for the enhancement evaluation were performed during a diastolic phase (reconstruction at $80 \%$ of RR interval).

Contrast opacification in the coronary arteries was subjectively scored on a 5-point scale $(1=$ poor, $5=$ excellent). Patients were interviewed after the examination to determine patient (dis)comfort on a scale from 1 to $10(1=$ severe discomfort, $10=$ no discomfort at all $)$. Any allergoid reactions and contrast extravasations were recorded.

Table 2 Contrast medium injection protocol

\begin{tabular}{|c|c|c|c|c|c|c|c|}
\hline \multirow{3}{*}{$\begin{array}{l}\text { Injection } \\
\text { phase }^{\mathrm{a}}\end{array}$} & \multirow{3}{*}{$\begin{array}{l}\text { Weight } \\
\text { group }(\mathrm{kg})\end{array}$} & \multirow{3}{*}{$\begin{array}{l}\text { Iodine flux } \\
I(\mathrm{~g} / \mathrm{s})\end{array}$} & \multirow{2}{*}{\multicolumn{2}{|c|}{$\frac{\text { Flow rate } F(\mathrm{ml} / \mathrm{s})}{\text { Contrast medium concentration }}$}} & \multirow{2}{*}{\multicolumn{2}{|c|}{$\begin{array}{l}\text { Volume } V(\mathrm{ml})^{\mathrm{b}} \\
\text { Contrast medium concentration }\end{array}$}} & \multirow[t]{3}{*}{ Injection duration $T$ (s) } \\
\hline & & & & & & & \\
\hline & & & $300 \mathrm{mg} / \mathrm{ml}$ & $370 \mathrm{mg} / \mathrm{ml}$ & $300 \mathrm{mg} / \mathrm{ml}$ & $370 \mathrm{mg} / \mathrm{ml}$ & \\
\hline \multirow[t]{3}{*}{ I } & $<70$ & 1.6 & 5.3 & 4.3 & $85-101$ & $69-82$ & \multirow[t]{3}{*}{ Imaging duration $+8^{\mathrm{c}}$} \\
\hline & $70-85$ & 1.8 & 6.0 & 4.9 & $96-114$ & $78-93$ & \\
\hline & $>85$ & 2.0 & 6.7 & 5.4 & $107-127$ & $86-103$ & \\
\hline \multirow[t]{3}{*}{ II } & $<70$ & 0.8 & 2.7 & 2.2 & 27 & 22 & \multirow[t]{3}{*}{10} \\
\hline & $70-85$ & 0.9 & 3.0 & 2.4 & 30 & 24 & \\
\hline & $>85$ & 1.0 & 3.3 & 2.7 & 33 & 27 & \\
\hline
\end{tabular}

The injected amount of iodine $M$ (total iodine dose) per phase can be calculated from $T$ and iodine flux $I$ : $M=T \times I$. Iodine flux $I$ and total iodine dose $M$ are independent of contrast material concentration and are the same for both contrast material concentrations

${ }^{a}$ Phase II immediately followed phase I and a saline flush of $30 \mathrm{ml}$ with the same flow rate as phase II was always performed immediately after phase II

${ }^{b}$ Volume is given as range. For an individual patient exact contrast material volume in each phase can be calculated from injection duration $T$ and flow rate $F$ as follows: $V=\mathrm{T} \times \mathrm{F}$

${ }^{\mathrm{c}}$ Start delay for bolus tracking was set to $8 \mathrm{~s}$ after reaching a threshold level of $100 \mathrm{HU}$ in an ROI in the descending aorta at the start of the planned imaging range (i.e. $15 \mathrm{~mm}$ above the highest coronary artery) 
Statistical analysis

Continuous variables were summarised by using mean and standard deviation, and categorical variables by using median and range. An independent $t$ test was used to compare the two groups in the case of continuous measures such as vascular enhancement for each measurement location. In the case of categorical variables, such as subjective scores for opacification, a Wilcoxon rank sum test was used to compare the two groups. A $p$ value less than 0.05 was considered significant. Data analysis was performed in SPSS for Windows (Version 12.0.1, 2004, Chicago, IL, USA).

\section{Results}

Patient characteristics of the included patients are summarised in Table 3. Patient comfort scores were a median of 7 in both groups $(p>0.05)$. No contrast extravasations occurred. Four patients developed a mild allergoid reaction (nausea or urticaria), three patients in the high concentration group and one patient in the moderate concentration group. Intended contrast medium injection rates were always reached including the maximum injection rate of $6.7 \mathrm{ml} / \mathrm{s}$. Mean time to threshold was $19 \mathrm{~s}$ (range 16-25 s) for the $300 \mathrm{mg} \mathrm{I} / \mathrm{ml}$ group and $20 \mathrm{~s}$ (range 15-25 s) for the $370 \mathrm{mg} \mathrm{I} / \mathrm{ml}$ group $(p>0.05)$.

Vascular enhancement

In the overall population mean attenuation in the aorta and left ventricle was significantly higher $(p<0.001)$ in the subjects in the moderate concentration group (Fig. 1). This significantly higher mean attenuation was also found in the two higher weight groups $(\geq 70 \mathrm{~kg}) \quad(p<0.05)$. This difference was not found in the lowest weight group $(<70 \mathrm{~kg})(p>0.05)$. The mean attenuation at the various levels in the right ventricle and in the pulmonary artery were never shown to be significantly different $(p>0.05)$. Despite the use of a weight-adapted contrast medium injection protocol with increasing iodine flux and iodine dose for heavier patients the attenuation decreased with increasing weight (Fig. 2). Figure 3 provides examples of CT images from both groups.

\section{Subjective scores}

In both groups scores of 3 (i.e. adequate) or more were given for the contrast opacification in the coronary arteries. The subjective scores of the coronary arteries were on average slightly, but not significantly, higher in the lower contrast medium concentration group (4.1 vs. 3.7 ) $(p>0.05)$.

\section{Discussion}

In this study we found a difference in arterial enhancement between high and moderate contrast medium concentrations in favour of the moderate concentration. This was seen despite injection protocols based on identical iodine flux and iodine dose, which theoretically should yield no difference in enhancement. Our finding seems to contradict the conclusion of previous studies comparing different contrast medium concentrations for cardiac CT in which better enhancement with higher concentration contrast medium was found $[8,9]$. However, these studies kept contrast injection rate or injection duration constant, therefore increasing the iodine flux and/or iodine dose for the high concentration protocol.

Each of the contrast medium concentrations has its advantages and disadvantages. Moderate concentration contrast media are currently used for most types of CT examinations, which results in a logistic advantage if the contrast medium (concentration) does not need to be

Table 3 Patient characteristics overall and per weight category

\begin{tabular}{|c|c|c|c|c|c|c|c|c|}
\hline \multirow[t]{2}{*}{ Characteristic $^{\mathrm{a}}$} & \multicolumn{2}{|c|}{ Overall $(n=159)$} & \multicolumn{2}{|c|}{$<70 \mathrm{~kg}(n=22)$} & \multicolumn{2}{|c|}{$70-85 \mathrm{~kg}(n=77)$} & \multicolumn{2}{|c|}{$>85 \mathrm{~kg}(n=60)$} \\
\hline & $300 \mathrm{mg} \mathrm{I} / \mathrm{ml}$ & $370 \mathrm{mg} \mathrm{I} / \mathrm{ml}$ & $300 \mathrm{mg} \mathrm{I} / \mathrm{ml}$ & $370 \mathrm{mg} \mathrm{I} / \mathrm{ml}$ & $300 \mathrm{mg} \mathrm{I} / \mathrm{ml}$ & $370 \mathrm{mg} \mathrm{I} / \mathrm{ml}$ & $300 \mathrm{mg} \mathrm{I} / \mathrm{ml}$ & $370 \mathrm{mg} \mathrm{I} / \mathrm{ml}$ \\
\hline Total no. (men) & $84(61)$ & $75(60)$ & $15(7)$ & $7(5)$ & $40(31)$ & $37(27)$ & $29(23)$ & $31(31)$ \\
\hline Age (years) & $58.2(9.4)$ & $57.0(9.5)$ & $61.8(5.6)$ & $61.3(11.9)$ & $57.5(7.4)$ & $57.3(9.6)$ & $57.4(12.7)$ & $55.7(8.9)$ \\
\hline Heart rate (bpm) & $57.6(8.4)$ & $57.5(7.6)$ & $59.7(10.6)$ & $62.9(4.3)$ & $56.6(7.6)$ & $58.1(8.0)$ & $57.9(8.3)$ & $55.6(7.2)$ \\
\hline Weight (kg) & $\begin{array}{l}81.5(12.6) \\
{[60-115]}\end{array}$ & $\begin{array}{l}83.0(11.4) \\
{[59-118]}\end{array}$ & $\begin{array}{l}65.4(3.4) \\
{[60-69]}\end{array}$ & $\begin{array}{l}62.9(3.7) \\
{[59-68]}\end{array}$ & $\begin{array}{l}77.6(5.0) \\
{[70-85]}\end{array}$ & $\begin{array}{l}78.2(4.5) \\
{[70-85]}\end{array}$ & $\begin{array}{l}95.2(8.6) \\
{[86-115]}\end{array}$ & $\begin{array}{l}93.3(7.9) \\
{[86-118]}\end{array}$ \\
\hline BMI $\left(\mathrm{kg} / \mathrm{m}^{2}\right)$ & $26.9(3.5)$ & $26.9(3.2)$ & $23.5(2.2)$ & $23.3(3.0)$ & $26.1(2.6)$ & $25.9(2.2)$ & $29.6(3.2)$ & $28.9(2.9)$ \\
\hline
\end{tabular}

Numbers are means with standard deviation between parentheses (and for weight the range is between brackets). Only in the first row are total numbers given with number of men between parentheses

$B M I$ body mass index

${ }^{a}$ No significant differences were found between the $300 \mathrm{mg} \mathrm{I} / \mathrm{ml}$ group and the $370 \mathrm{mg} \mathrm{I} / \mathrm{ml}$ group regarding these characteristics 
changed for cardiac CTA. However, the use of lower concentration contrast media for cardiac CTA requires high injection rates and thus large needles that can facilitate these high injection rates. The use of high concentration contrast medium, on the other hand, allows lower flow rates and thus smaller needles. Also smaller contrast medium volumes are needed for administration of an identical iodine dose. High concentration contrast medium doses, however, need to be preheated because of its high viscosity at room temperature. Costs of the two concentrations are probably comparable: high concentration contrast medium is generally more expensive per volume unit but a smaller volume can be applied per patient.

Previous studies on arterial contrast enhancement in cardiac and abdominal CT with varying concentrations of iodinated contrast medium but equal iodine flux and equal iodine dose have shown conflicting results. Two studies with an iodine flux of $1 \mathrm{~g} / \mathrm{s}$ in cardiac CT did not show an advantage for a moderate or high concentration contrast medium [13, 14]. Several studies in either chest or abdominal CT, one by Suzuki et al. [15] and three recent studies [16-18], did not find a significant difference in arterial enhancement either. However, a study by Awai et al. in abdominal CT, with a very similar set-up as the aforementioned study by Suzuki et al., did find a benefit for rapid administration of lower concentration contrast medium [19]. Also, a recent intra-individual comparison in combined thoraco-abdominal CT by Behrendt et al. found a better enhancement in the thoracic vessels for contrast medium with a concentration of $300 \mathrm{mg} \mathrm{I} / \mathrm{ml}$ compared with that with a concentration of $370 \mathrm{mg} \mathrm{I} / \mathrm{ml} \mathrm{[20].} \mathrm{It} \mathrm{is}$ unclear why our study and the studies by Awai et al. and by
Fig. 1 Bars display average enhancement at each measurement location per contrast medium concentration group for all subjects (a), and the three weight categories (b-d); error bars display one standard deviation. Significantly higher enhancement was found in the lower concentration contrast medium group (black bars) at the measurement locations in the aorta and left ventricle for the overall group and the two higher weight categories but not in the lowest weight category. (Asc Ao ascending aorta, Desc $A o$ descending aorta, $L V$ left ventricle, $R V$ right ventricle, Pulm Art pulmonary artery, cran cranial, $m$ mid, caud caudal) a

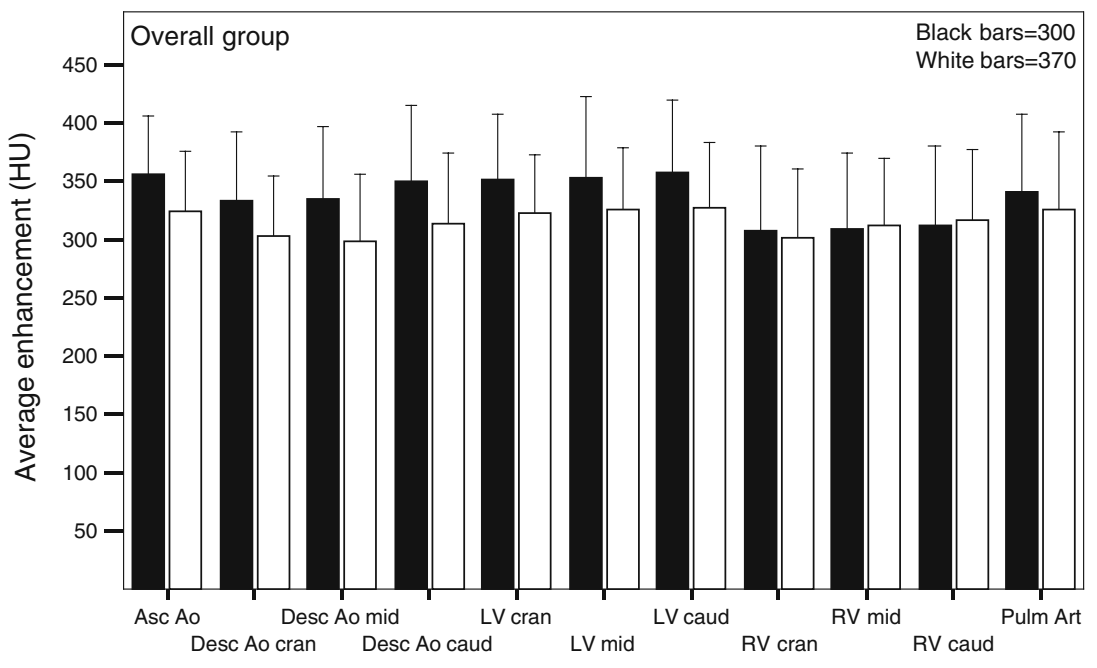

Measurement location

b

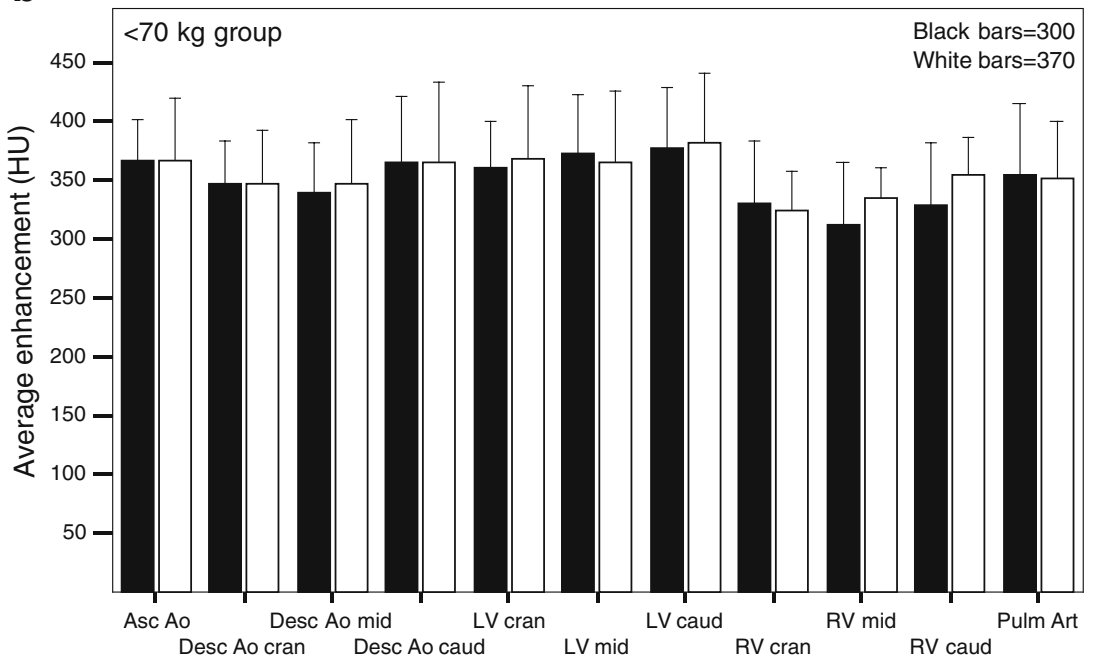

Measurement location 
Fig. 1 (continued)
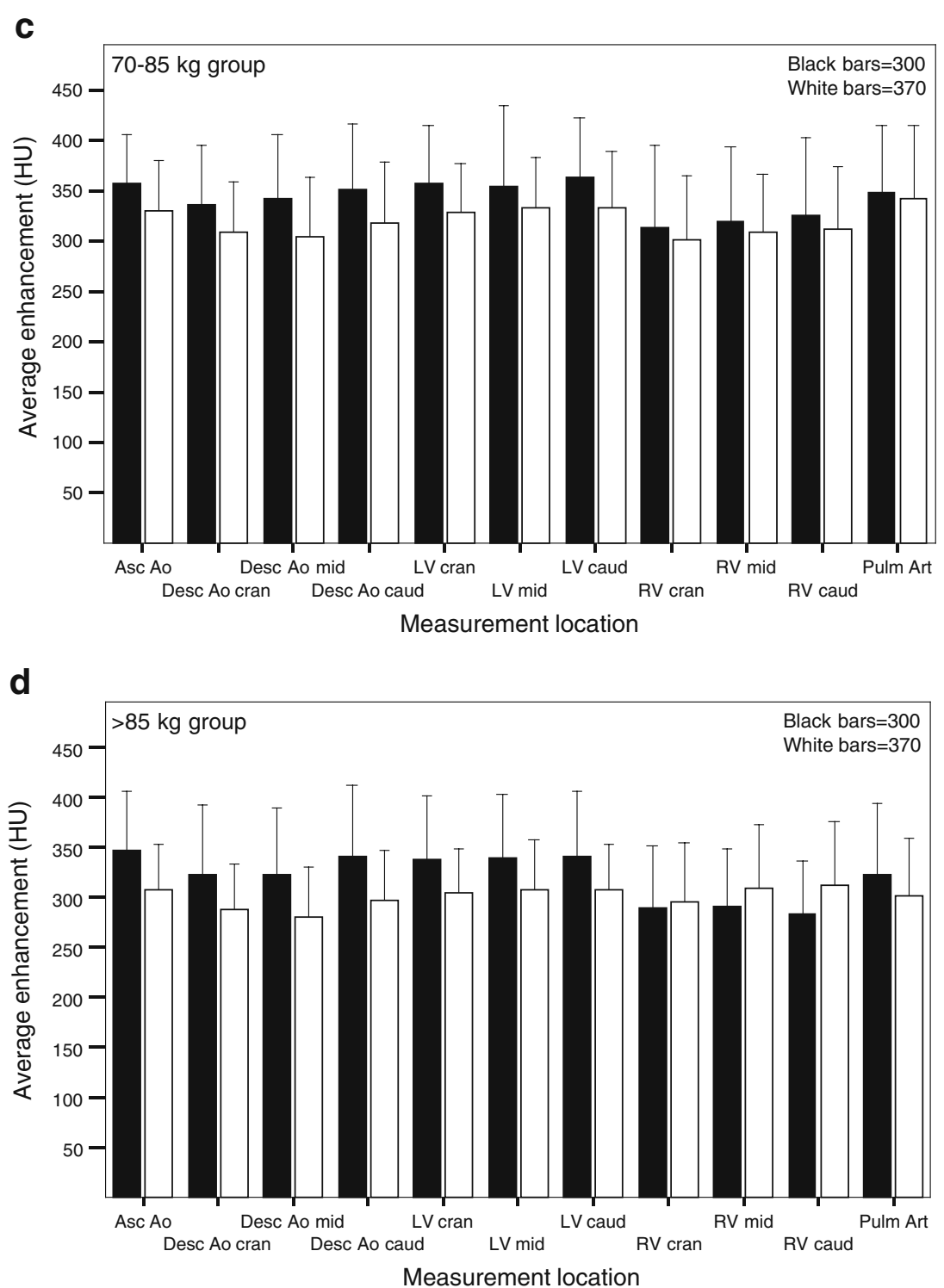

Behrendt et al. did detect a difference in arterial enhancement in favour of the lower concentration contrast medium while the other studies did not.

It is difficult to provide an explanation for the difference in enhancement found in our study especially because we designed this study to show equal enhancement of the two concentrations. To better understand the dynamic nature of the contrast enhancement, one would need to perform a dynamic imaging procedure of a fixed volume or at a reference level. However, such a dynamic procedure would entail a substantial additional radiation dose and extra contrast medium load for each patient and would have to be performed before the actual cardiac CT. For this reason, we can only discuss a number of potential explanations for our results: the difference in contrast material volumes, the difference in viscosity, differences in venous pooling or the dead venous space phenomenon [19].
At identical iodine flux and iodine dose, the injected contrast material volume is higher, both in total as well as per unit time, for lower concentration media. At a constant cardiac output, a higher volume of contrast medium entering the heart per unit time will lead to less blood mixing with the contrast material and therefore will cause a higher contrast concentration in the central blood compartment. This "volume effect" has been suggested by Bae [21] as an explanation of the effect seen by Awai et al. [19]. Cardiac output, however, does not necessarily have to stay constant during contrast medium injection: in young healthy individuals, a sudden volume load may induce an increase in heart rate and cardiac output while the same sudden volume load may induce a drop in cardiac output in older patients with a failing heart. As cardiac output and enhancement are linked [22], the effect could go either way: increasing or decreasing enhancement. 

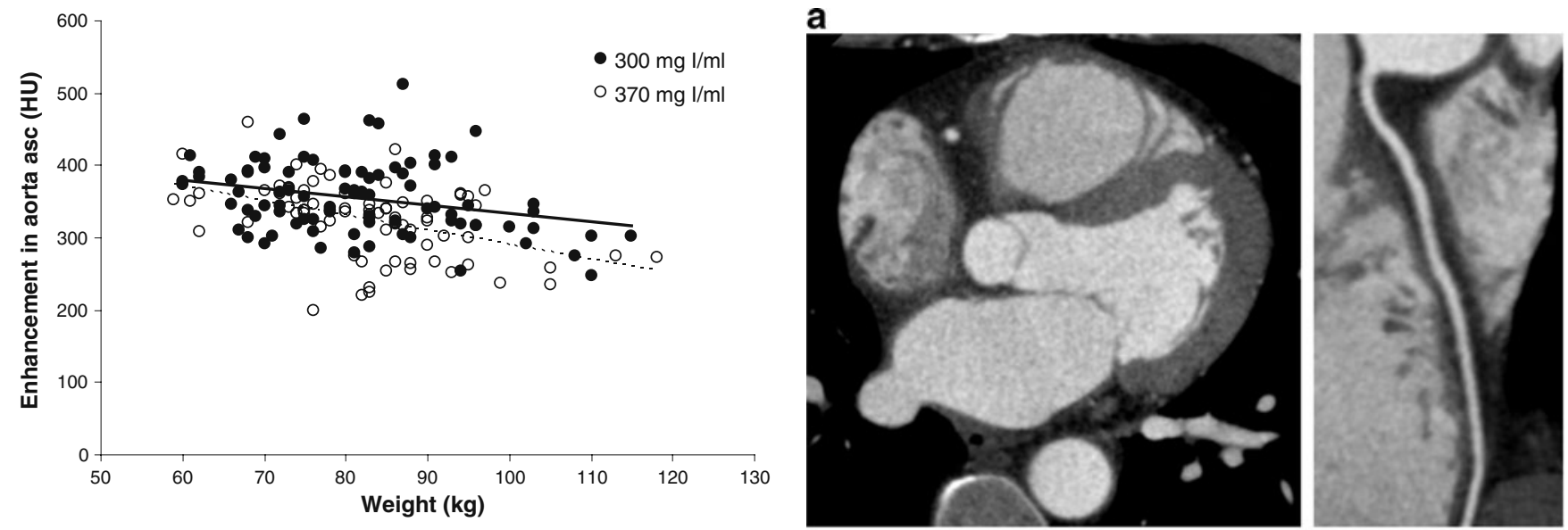

Fig. 2 Enhancement in the ascending aorta versus weight. Note that the trend lines for both concentrations show that enhancement decreases with increasing weight in both contrast medium concentration groups despite the use of three weight categories in the injection protocol

The higher viscosity of higher concentration contrast media could hamper rapid administration and lengthen the transit time of the contrast medium [7, 23]. The maximum flow rate in a vein phantom was found to decrease at higher contrast medium concentration: at $370 \mathrm{mg} \mathrm{I} / \mathrm{ml}$ the highest iodine flux was $2.2 \mathrm{~g} / \mathrm{s}$ or $6 \mathrm{ml} / \mathrm{s}$; at $300 \mathrm{mg} \mathrm{I} / \mathrm{ml}$ an iodine flux of $2.4 \mathrm{~g} / \mathrm{s}$ or $8 \mathrm{ml} / \mathrm{s}$ was reached [23]. However, these maximum injection rates are above the injection rates used in our study for both the high and moderate concentration groups and data produced by the contrast medium injection pump confirm that the required injection rates were always reached. In addition, we preheated the $370 \mathrm{mg} / \mathrm{ml}$ contrast medium to $37^{\circ} \mathrm{C}$ to obtain a viscosity similar to that of $300 \mathrm{mg} / \mathrm{ml}$ contrast medium at room temperature. The fact that we found no significant difference in time to threshold between the two groups supports the notion of identical arrival times and discourages the idea that the more viscous contrast material travelled more slowly.

Venous pooling occurs when contrast material is "trapped" in small veins where it travels more slowly and therefore contributes less to downstream enhancement. This effect could lead to lower enhancement for more viscous contrast material or for higher flow rates: more viscous high concentration contrast medium on its way to the heart could be trapped in small veins or could stick to the vessel wall. With an increase in flow rate one could argue that a higher pressure is built up in the injection vein during the infusion of contrast medium and contrast medium may be pushed into smaller veins. The contrast medium may remain trapped in these small veins until the pressure in the injection vein drops.

The dead venous space phenomenon refers to the contrast material that remains in the dead venous space at the end of a contrast medium injection [19]. This contrast

b
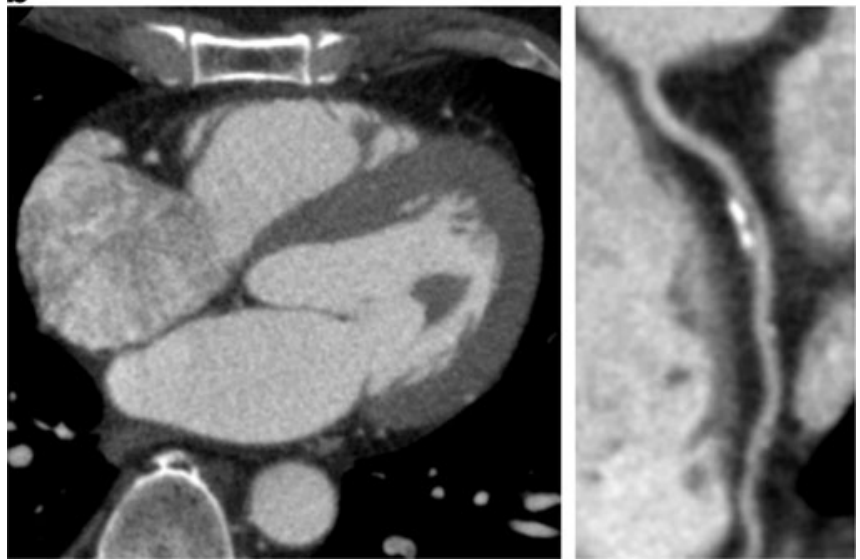

Fig. 3 Examples of axial CT images (left) and curved planar reformations of the right coronary artery (right) with both $300 \mathrm{mg} \mathrm{I} / \mathrm{ml}$ contrast medium (a) and $370 \mathrm{mg} \mathrm{I} / \mathrm{ml}$ contrast medium (b). Note that with both concentrations of contrast medium sufficient contrast enhancement of the heart is reached. The right coronary artery is little affected by the presence of contrast medium in the right atrium and ventricle

material no longer travels at the original flow rate but, at most, at the speed of the venous blood towards the heart and therefore contributes less to enhancement than the earlier contrast material that was injected quickly. This effect increases with the use of high flow rates that are substantially above the flow rate of venous blood. In a dual (or triple) phase injection, the second phase is also subject to such a dead space phenomenon if the injection rate is decreased between phases: contrast material in the injection veins travels no faster than the flow of the second phase of the injection. Because the volume of the dead space is identical for the two contrast injection protocols, the proportion of iodine contained in a given dead space is larger for higher concentration contrast material due to the lower volume being injected. In the high concentration group less iodine is therefore travelling with the high flux of the first phase. The iodine in the venous 
dead space reaches the heart later, which may explain why right ventricular and pulmonary enhancement did not show a difference. Recently a split bolus injection protocol with multiple phases with identical flow rates but with different contrast concentrations between phases was described [2]. If the dead space phenomenon is the explanation for the difference in enhancement found in our study, its occurrence can be prevented by using this split bolus injection protocol with identical injection rates between phases.

This study has several limitations. First, instead of applying a continuous increase in injection rates with increasing patient weight, we used three weight categories. In particular, the highest weight category contained patients with a large range in weight. A slight decrease in attenuation was found with increasing weight throughout each category. The reason why we opted for three categories was mainly logistic: six preprogrammed injection protocols in the injector sufficed. Besides, a continuous increase in injection rates with increasing weight would have resulted in too high injection rates in very heavy patients. Also, a large variability in enhancement exists between patients with similar weights, as weight is not the only patient-related factor that has an effect on enhancement [24].
Another limitation is the small size of the lowest weight group. Relatively few patients have a weight below $70 \mathrm{~kg}$ especially in this patient group with cardiovascular disease. The results in the low weight group below $70 \mathrm{~kg}$ were not consistent with the results in the other two groups. However, this did not seem to be caused by the small size of the group, but rather by a true difference between the weight groups. Lower injection rates, less dead space and a relatively large iodine dose per kilo patient weight might be underlying factors.

In conclusion, high concentration contrast material appears to yield less arterial enhancement compared with moderate concentration contrast material with a biphasic injection protocol with reduction of the flow during the second injection phase and with equal iodine flux and iodine dose for both contrast material concentrations.

Acknowledgement This study was financially supported by BayerSchering AG, Berlin, Germany. P.R. Seidensticker is an employee of Bayer-Schering.

Open Access This article is distributed under the terms of the Creative Commons Attribution Noncommercial License which permits any noncommercial use, distribution, and reproduction in any medium, provided the original author(s) and source are credited.

\section{References}

1. Vrachliotis TG, Bis KG, Haidary A, Kosuri R, Balasubramaniam M, Gallagher M, Raff G, Ross M, O’Neil B, O'Neill W (2007) Atypical chest pain: coronary, aortic, and pulmonary vasculature enhancement at biphasic single-injection 64-section CT angiography. Radiology 243:368-376

2. Kerl JM, Ravenel JG, Nguyen SA Suranyi P, Thilo C, Costello P, Bautz W, Schoepf UJ (2008) Right heart: split-bolus injection of diluted contrast medium for visualization at coronary CT angiography. Radiology 247:356364

3. Herman S (2004) Computed tomography contrast enhancement principles and the use of highconcentration contrast media. J Comput Assist Tomogr 28(Suppl 1):S7-S11

4. Brink JA (2003) Contrast optimization and scan timing for single and multidetector-row computed tomography. J Comput Assist Tomogr 27(Suppl 1): S3-S8
5. Husmann L, Alkadhi H, Boehm T, Leschka S, Schepis T, Koepfli P, Desbiolles L, Marincek B, Kaufmann P, Wildermuth S (2006) Influence of cardiac hemodynamic parameters on coronary artery opacification with 64-slice computed tomography. Eur Radiol 16:1111-1116

6. Fleischmann D (2003) Use of high concentration contrast media: principles and rationale-vascular district. Eur J Radiol 45(Suppl 1):S88-S93

7. Blomley MJ, Dawson P (1997) Bolus dynamics: theoretical and experimental aspects. Br J Radiol 70:351-359

8. Cademartiri F, de Monye C, Pugliese F, Mollet NR, Runza G, van der LA, Midiri M, de Feyter PJ, Lagalla R, Krestin GP (2006) High iodine concentration contrast material for noninvasive multislice computed tomography coronary angiography: iopromide 370 versus iomeprol 400. Invest Radiol 41:349-353

9. Cademartiri F, Mollet NR, van der Lugt A, McFadden EP, Stijnen T, de Feyter PJ, Krestin GP (2005) Intravenous contrast material administration at helical 16detector row CT coronary angiography: effect of iodine concentration on vascular attenuation. Radiology 236:661-665
10. Garcia MJ, Lessick J, Hoffmann MHK, for the CATSCAN Study Investigators (2006) Accuracy of 16-row multidetector computed tomography for the assessment of coronary artery stenosis. JAMA 296:403-411

11. Mollet NR, Cademartiri F, van Mieghem CAG, Runza G, McFadden EP, Baks T, Serruys PW, Krestin GP, de Feyter PJ (2005) High-resolution spiral computed tomography coronary angiography in patients referred for diagnostic conventional coronary angiography. Circulation 112:2318-2323

12. Leber AW, Knez A, von Ziegler F, Becker A, Nikolaou K, Paul S, Wintersperger B, Reiser M, Becker CR, Steinbeck G, Boekstegers P (2005) Quantification of obstructive and nonobstructive coronary lesions by 64-slice computed tomography: a comparative study with quantitative coronary angiography and intravascular ultrasound. J Am Coll Cardiol 46:147-154 
13. Rist C, Nikolaou K, Kirchin MA, van GR, Bae KT, von ZF, Knez A, Wintersperger BJ, Reiser MF, Becker CR (2006) Contrast bolus optimization for cardiac 16-slice computed tomography: comparison of contrast medium formulations containing 300 and 400 milligrams of iodine per milliliter. Invest Radiol 41:460-467

14. Becker CR, Hong C, Knez A, Leber A, Bruening R, Schoepf UJ, Reiser MF (2003) Optimal contrast application for cardiac 4-detector-row computed tomography. Invest Radiol 38:690-694

15. Suzuki H, Oshima H, Shiraki N, Ikeya C, Shibamoto Y (2004) Comparison of two contrast materials with different iodine concentrations in enhancing the density of the aorta, portal vein and liver at multi-detector row CT: a randomized study. Eur Radiol 14:20992104

16. Behrendt F, Mahnken A, Keil S, Das M, Hohl C, Bauer D, Seidensticker P, Jost E, Wildberger J, Guenther R, Muehlenbruch G (2008) Contrast enhancement in multidetector-row computed tomography (MDCT) of the abdomen: intraindividual comparison of contrast media containing $300-\mathrm{mg}$ versus 370-mg iodine per ml. Eur Radiol 18:1199-1205
17. Behrendt FF, Plumhans C, Keil S, Mühlenbruch G, Das M, Seidensticker P, Mutscher C, Günther RW, Mahnken AH (2009) Contrast enhancement in chest multidetector computed tomography: intraindividual comparison of $300 \mathrm{mg} / \mathrm{ml}$ versus $400 \mathrm{mg} / \mathrm{ml}$ iodinated contrast medium. Acad Radiol 16:144-149

18. Muehlenbruch G, Behrendt F, Eddahabi M, Knackstedt C, Stanzel S, Das M, Seidensticker P, Günther R, Wildberger J, Mahnken A (2008) Which Iodine concentration in chest CT? A prospective study in 300 patients. Eur Radiol 18:2826-2832

19. Awai K, Inoue M, Yagyu Y, Watanabe M, Sano T, Nin S, Koike R, Nishimura Y, Yamashita Y (2004) Moderate versus high concentration of contrast material for aortic and hepatic enhancement and tumor-to-liver contrast at multi-detector row CT. Radiology 233:682-688

20. Behrendt FF, Mahnken AH, Stanzel S, Seidensticker P, Jost E, Gunther RW, Muhlenbruch G (2008) Intraindividual comparison of contrast media concentrations for combined abdominal and thoracic MDCT. AJR Am J Roentgenol 191:145-150

21. Bae KT (2005) Comparison of moderate versus high concentration of contrast media injected at the same total iodine dose and fixed injection duration. Radiology 236:740-741. doi:10.1148/radiol.2362050096
22. Bae KT, Heiken JP, Brink JA (1998)

Aortic and hepatic contrast medium enhancement at CT. Part II. Effect of reduced cardiac output in a porcine model. Radiology 207:657-662

23. Knollmann F, Schimpf K, Felix R (2004) Iodine delivery rate of different concentrations of iodine-containing contrast agents with rapid injection. Rofo 176:880-884

24. Bae KT, Seeck BA, Hildebolt CF, Tao C, Zhu F, Kanematsu M, Woodard PK (2008) Contrast enhancement in cardiovascular MDCT: effect of body weight, height, body surface area, body mass index, and obesity. AJR Am J Roentgenol 190:777-784 